\title{
AN EMBODIED ARCHITECTURE
}

\author{
Frances Downing ${ }^{1}$, Upali Nanda ${ }^{2}$, Narongpon Laiprakobsup ${ }^{3}$, Shima B. Mohajeri ${ }^{4}$ \\ ${ }^{1}$ Department of Architecture, Texas A\&M University, USA \\ 2 Vice President, Director of Research, American Art Research, USA \\ ${ }^{3}$ Department of Architecture, Kasetsart University, Thailand \\ ${ }^{4}$ Ph.D. Student, Department of Architecture, Texas A\&M University, USA
}

\begin{abstract}
An architecture of the body is emerging out of theories of biology, complexity, and systems through the use of an evolving organism as its metaphor. Autopoiesis is the term used by biologists to describe the realm of existence for a living organism as it slides between the interchange of structure and information. Incoming information is filtered through the organism for its usefulness in the art of staying alive. Structural or organizational changes evolve as the organism adjusts to new information. To remain a viable organism-to survive-means that an entity must keep evolving without surrendering identity. Humans must maintain an embodied identity, often referred to as an organized self (Maturana \& Varela, 1980, 1987), while viably exchanging information with other entities and the environment. This operation creates a topological boundary across which the communication takes place.
\end{abstract}

Cognitive theorists and researchers have proposed that the animal condition is one of Embodied Realism; that is, animals such as we humans, are embodied, using our bodies to create basic metaphors, and, that we do this in a "real" world. The role of cognition in this equation is to allow humans the use of embodiment to explore abstract ideas through metaphor-such as "grasping an idea" (Lakoff \& Johnson, 2003). In doing so, it allows the invention of an evolving language that refers to things "outside" our skin, like other entities and places. Autopoiesis describes the activities at the "edge" or boundary of an organism. The linguistic act can, therefore, be identified as fundamental medium for communication in the edge, between inside and outside, that assures the autopoiesis of place.

In our own bodies, flesh is the biological manifest of the edge or boundary condition. Our understanding of flesh is that it is another of our organs; and at the same time, all organs are also bounded by flesh. It serves as a porous filter, delicate and complicated-it is our body boundary. The "flesh" or the lived body (Merleau-Ponty, 1968) is moreover, an inbetween concept that articulates the subjective mind to the objective world. It bridges the boundaries separating inside from outside. Thus, it could act as a metaphor for introducing the notion of edge in architectural place. The edge itself then, embodies the embodied being. Buildings have boundaries of foundation, wall, or roof, parts of which could be thought of as the "skin." In today's practice, the various skins of a building have become more complicated and porous as the field of architecture extends itself into "systemic" conditions, within and without. It follows then that the body survives the interaction and communication between mind and the external world if it inhabits the edge of place embodying localized boundary metaphors.

Architecture is beginning the process of aligning itself with a new moral code-one that is inclusive of our biological reality, the embodiment of ideas, systemic evolution, and ecological necessities. This paper is situated within this new moral code of systemic ecological and biological interactions.

Keywords: Embodiment, Body, Metaphor, Evolution, Autopoiesis, Survival.

\section{Systems Theory}

Systems come in two types, simple and complex. Simple systems are those where the complexes of elements standing in interaction do not rely upon information, cause, or interaction from outside the system. These systems-for example, an automobile engine-refer to predictable behavior because there are a limited number of variables in cause and effect relationships. Simple systems are determinant and cannot adapt or evolve 
(www.complexityandeducation). Complex systems, in contrast, are open networks where elements stand in interaction and do exchange information, intentions, cause, or effect from or to the domains in which a system resides-generating a creative and active evolution. These systems have component parts yet the interactions and boundaries are complex-where does one system stop and another begin. The parts in complex systems do not have evident boundaries, it cannot be dismantled like an engine can, each part folds into the next neither ending nor beginning. Boundaries in complex systems become complex layers of bonding the network. In figure 1 , the site plan of "Redgate House," 1 a design for the remodeling of a small bungalow and its property, for example, suggests that the boundaries of each place are systemically complexwhere does one area begin and another end (Fig.1)?

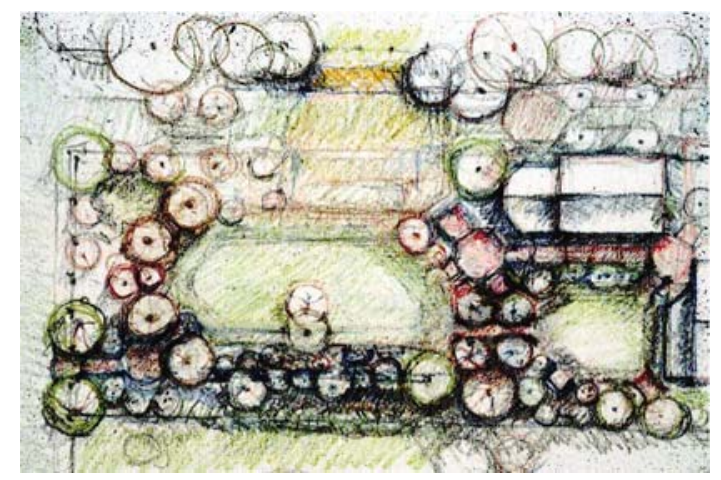

Figure 1: The site plan of the Regate House manifests complex boundaries: where does one thing end and another begin?

The notion of fluid boundaries in a complex system accounts for its internal dynamism and synthetic continuity among the elements, which prompt a creative transformation within the system. The process of selfmodification and self-organization inside the system perpetuates the mutual interaction with the environment that results in the invention of new structures (Bergson, 1922). Therefore, since the organism is thought of as an

1 "Redgate" was a bungalow house owned by Thomas Hubka, who was an assistant professor at the University of Oregon in 1970's. The Regate House manifests itself an example that articulate the conception of cultivating "Significant form" of place and the process of constructing an embodied place and its networks-through the development of the presence of complex, living edges/boundaries. active participant in the evolutionary process, it establishes a divorce with the Darwinian conception of evolution in which the environment imposingly determines the change in the living beings. In contrast, the 'mutual interpenetration' of the living system with its milieu specifies a communicative domain, which leads to 'mutual specification' and 'codetermination' (Varela et. al., 1993) in a non-hierarchical relation. This mutual specification, which represents continuity, movement and flux in an ever-changing flow, occurs at the intersection of the living system and the environment in an interstitial domain.

The structure in a complex system is not a linear set of connections or dependencies; rather, it is described as a web of interdependences within a neighborhood of nested components. We imagine that each nested entity-each neighborhood-flows into other neighborhoods and to larger and more encompassing environments around the body-all systematically connected. A full understanding of our own body and knowledge about how it locates itself in place would assist designers in making compelling logical form and more holistic significant form (Langer, 1953).

In architecture, we now know that we are responsible for a building "in place." In today's global context an ecological consciousness has emerged and we no longer can build merely to the site lines; now we ask ourselves where do the materials come from, how much does the building really cost in embodied energy, what is the footprint of this building on land, and on the resources of the land? No longer can we walk away from a completed project without monitoring its progress; that is, did we model the systems carefully and is it acting in place the way it was intended?

Now we are concerned with the building in its ecological position "in" place. Do we take advantage of natural systems to make the building "work?" How does our project affect other places in the designed and natural environment? At the other end, we have become concerned with the human being who inhabits the building, and how the building affects his/her physical, psychological and behavioral state. Many of these questions are relatively new in the world of design and, as such, these queries are causing a change in the way we design and make places. Such a shift in industry ethics is a change in approach-one that acknowledges the interdependence of systems and the importance of boundary conditions. The boundary between us, the buildings that envelop us, and the environments that 
contain this building, is fluid, defined by a series of transforming edge conditions. The most fundamental boundary between the lived body and inhabited place is the skin or the flesh. In language, this boundary often serves as a metaphor for understanding edge conditions betwixt two external entities. In effect our corporal body is the medium through which we understand abstract concepts, and the edge condition is frequently defined through its biological manifest (the skin or flesh, both literally and metaphorically). Linguistic act (or the body metaphors) is an illustration of the notion of flesh or the mind-body interaction. The corporeal body acts as a mediator that conveys ideas and concepts to the outside world. Therefore, in order to generate conceptual metaphors, the body should inhabit the edge condition in place. In this paper, we seek to understand the edge condition through its biological manifest-the flesh-via the linguistic act of creating conceptual metaphors, that is, embodiment of a living entity through complex boundaries.

\section{Embodiment}

To be autonomous and self-organizing beings humans must be bounded. Our autonomous boundary is our skin. Scientists tell us that the most complicated and rich information happens at the overlap of one system with another. For example, if we were walking in the forest and happened upon a meadow, if we choose to move towards the meadow the range of plant life, insect life, and interaction that might happen is concentrated at the edge. It is a difficult edge to define because the "inbetween" is difficult to judge; when have you "left" the forest and entered the meadow? The edge condition of our bodies is a combination of the skin, always in transition, and our other system exchange capacities (vision, kinesthetic, audition, scent, and taste). Along with our other exchange routes, it is our body boundary. The flesh exists between our "in"-side and our "out"-side. Because the mind is embodied we think metaphorically, through our body orientations and actions.

In Philosophy and the Flesh, Lakoff \& Johnson make an argument for an "Embodied Realism" which discounts the idea of a reality that is divided into categories independent of the "specific properties of human minds, brains, or bodies" (1999, pp. xiv, 624). The core ontological assumption is that we are coupled to the world through our embodied interactions. The mind and the body are not separate entities, rather the mind is considered as embodied. In this sense, our conceptual structures can be understood as arising from our sensorimotor (combining sensation and movement) experience and the neural structures that give rise to it. Our mental structures become intrinsically meaningful by virtue of their connection to our bodies and our embodied experience, and reason is embodied because our fundamental forms of inference arise from sensorimotor and other body-based forms of inference. An intrinsic valuation of our spatial coordinates takes place once mediated through our bodies.

One walks into the front of a church and finds oneself in the back of the sitting area, which "faces" the podium. Our inexact bisymmetry favors our "right" sides-we will say to someone that the book they are looking for is "right over there"...here you have a string of body metaphors... It does not matter if the book is actually to the left, we often even point a finger (usually a forefinger) when we say "right"..."over" is a term that is tied to how our bodies and other living entities move... and "there" is a reference to location in relation to our bodies which are "here." Up is good; down is not so good. We use up and down as descriptive of emotional states, as directors or locators, and as good vs. bad. If we say, we stand side-by-side on an issue it means we agree or share, and mean to defend a "stance." The body-based properties and basic level categories help us build, metaphorically, conceptual constructs in the abstract.

Examples are everywhere; if you say to someone that:

"I cannot grasp this theory."-you are trying to pull some ideas out of another person's mind or from the words on paper-or,

"I cannot understand this theory"-by not "standing under" you mean you are not finding a way to support the ideasor,

"I cannot fathom this theory"-you mean that somehow you cannot measure these ideas-or,

"I cannot follow this theory"-you mean that you cannot navigate through these ideas-or,

"I cannot decipher this theory"-you mean that you cannot make the ideas add-up to something.

In addition to all the different ways of describing some confusion built into our expressions in language we also have to resort to metaphor to explain the metaphor; i.e. to 
pull, support, measure, navigate, and add-up are all metaphors taken from our bodies in place and our environmental referrals to our embodiment. Often we cross sense modalities to express the same kind of abstracted idea; if you say that:

This theory is unclear-it is sensory-you cannot see it. This theory is too hard-it is sensory-you cannot feel it. This theory is too deep-it is spatial-it is bottomless. This theory is beyond me-it is spatial-it has gone too far. Beyond the orientation metaphors the body boundary allows us to pursue the "out there" through embodied concepts of structural schema- "war is hell" is where one concept is structured through another powerful metaphor (Lakoff \& Johnson, 1999).

We have a few famous structural metaphors in architecture-

"... a building is a machine for living" or,

"...less is more" or,

"...architecture is frozen music".

There are also ontological metaphors where we try to make sense of the intangible things in the world through personification-"life cheated me"-is a way of understanding emotional or experiential domains. Buildings have been dubbed as: "ethereal", "sublime", "pleasing", "brutal", "plain", and more. They have openings often called our eyes to the world-a building has a face, a building has skin, often a top, bottom, and sides. The places we make are often a reflection the kind of experience we allow our fully sensate bodies to have.

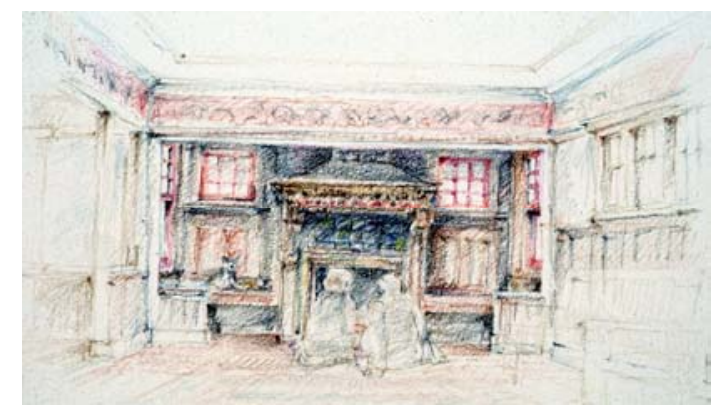

Figure 2: Container Schema of the Regate House's living space is defined by complex, living boundaries affording a sense of an enclosed entity and interaction, simultaneously.
Cognitive theorists describe three basic schemas that are body based-the container schema, the periphery/center schema, and the source/path/goal schema (Lakoff and Johnson, 2003). The drawing of the Redgate House's living room (Fig. 2) is a clear example of a container schema as well as the periphery/center schema. The house is a very small bungalow and this drawing presents studies of a remodeling. The living space is small so the edge has been expanded to be an interactive realm. The center of the room has been supported by the complex periphery as the drawing indicates it is expanded and enriched by an exterior bay and an interior bay. The ability to occupy the edge is enriched by these design moves and its ability to act as a container and as a refuge.

Complex systems share some principles that we can identify with: they must involve autonomous agents; in this case we are interpreting this as having "free will" even though we choose to have some external controls of laws and acceptable behavior standards, within these maxims we are free to move and act in our environments. Our acts in the environment are nonlinear-the whole is different from the sum of the parts. This can be explained by way of schema using source/path/goal; you might leave your office (source) with the express intention of going to the library (goal), however, the path may be littered with events or people that interrupt your intended goal. You might choose to join a friend for coffee that you have met along the path and not reach your goal at all, or at the least postpone the initial goal, or substitute another. An additional characteristic of complex systems is emergence; again, the parts are not equal to the whole; we cannot study the brain apart from the body because what emerges from embodiment in concert with place is our ability to think and communicate. In turn, we cannot study place apart from the body because what emerges from a systemic view is the complement of fully sensate understandings of what makes a place with significant form. We thus can experience significant form of place if we fully present ourselves as a lived body in place.

\section{The Body in Place, the Body for Place, the Body Dis-placed}

Western thinking has been flailing away at the traditional subject/object problem for centuries. Essentially, most science is practiced as if "an observer can, at least in 
principle, be objective and disembodied" (www.complexityandeducation). Collier calls these the "archetypical tensions between the Universal and the Particular...where...unlike the pure consciousness of angels, we are embodied concrete particulars. Human nature is collective-we are social beings connected in a complex dance with others and our environments" (Collier, 2000, p. 245). In his epic work of The Fate of Place Edward Casey fits the puzzle of embodiment with place. His intention is to clearly separate issues of place from space. Again, the problem of understanding embodiment comes from the deluge of Western philosophers as the subject/object problem.

According to Casey, both Descartes and Kant share the view of a "matheisis universalis" (Casey, 1998, p. xiv) as a way of explaining extended space through abstract $X Y Z$ geometric axes. Some philosophers in denying the emptiness of space use the body as the measure of "place" or location through "qualities of direction, fit, density, contiguity, and interstice" (Casey, 1998, p. 645). We constantly use our bodies as locators; if center/periphery schema was to be explored we would have to know where a "body" could locate itself. In figure 3, you see the designer engaging the viewer by adding individual characters, not just for scale, but to help anyone viewing this abstract section as an inhabitable place. The edge condition is enriched as it is a library with a built-in bay for reading. Adding compelling characters allows the viewer a location, an ability to embody this potential place (Fig.3).

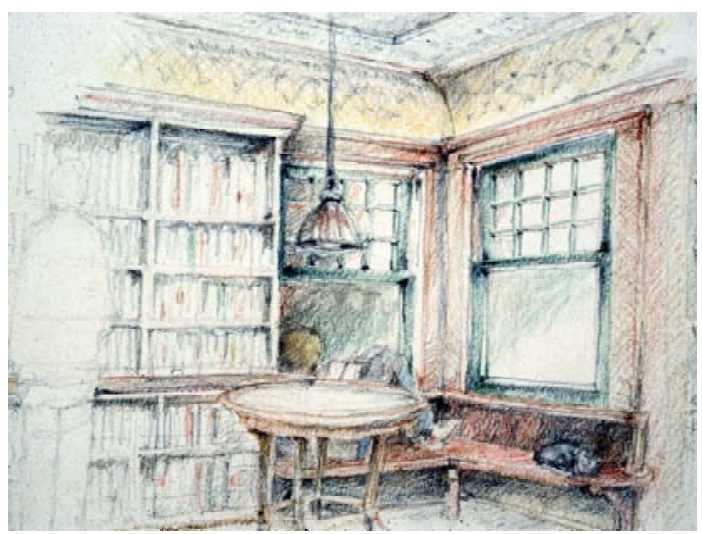

Figure 3: The Redgate House's edging corner develops a place that allows for the body to inhabit as the measure of "place" or location.
In his philosophy, Merleau-Ponty makes a case for the embodied nature of the visual and claims "quality, light, color, depth, which are there before us, are there only because they awaken an echo in our body and our body welcomes them" (Merleau-Ponty, 1964, pp. xix, 228). In doing so he breaks away from Cartesian dualism of subject and object by introducing the notion of a living boundaryflesh. In his seminal book, The Visible and the Invisible, he identified the flesh as an inbetween place as the boundary provides an overlapping domain for both subjective experience and objective existence. Merleau-Ponty used the term 'atmosphere', referring to the flesh as something neither object or idea, but a "possibility" of intertwined layers of body and the world. The flesh, then, acts as a metaphor for the edge of place in which the body does not serve as a container or instrument; rather it functions as a motivation for communication between inside and outside. The two dimensionality of the flesh is also conceived as the lived body that is simultaneously perceiving and perceived.

According to Francesco Varela, following Merleau-Ponty, the emergence of the 'embodied mind' as the more recent ideas of the cognitive science has spanned the interface between the 'disembodied observer' and the 'dis-worlded mind'. Varela has incorporated the notion of 'enaction' as a lived embodied action to the autopoiesis theory in order to question the viewpoint of a pre-given, perceiver independent world (Varela et all, 1993). In reality, as selforganizing particulars-our bodies_are tools for examining the places we are in through extensive use of analogy, but more effectively, through metaphor. In putting the mind and body back together again as a circular never-ending living system in touch with other systems, going from place to place, we can envision a more complete architecture-one that embodies significant places in form and content.

The notion of 'lived body' as the combination of Husserl's "lived body" and Bergson's "le vécu" or 'the lived' incarnates the mind within the common ground of embodiment. Once we lose a sense of this carnal echo, we dissociate the visual from what it means to be human. It is the same concern that consumes the writings of Heidegger, Sartre, Foucault, and Derrida, although each of these writings has its own ideological agenda.

With the technological advancements in the last century issues of embodiment have become more complex. Our interaction with the world around us is increasingly 
mediated and the boundary conditions have transformed. It is possible today to immerse ourselves in different realities simultaneously-through the internet we can browse the news in Asia, while listening to the Beatles on an ipod, and watching a soccer game on a high definition television. The different senses housed in our body can now live in parallel, but disconnected realities. The mind and body can live in different "worlds" where the body is dis-placed, and place is dis-embodied. We argue that as architects place can be the mediator between body and mind. In "The Turning" Heidegger argues that "both our capacity for seeing and our capacity for hearing are perishing through radio and film under the rule of technology" (cited in Levin, 1993, p. 3). In the Dawn and Decline, Max Horkheimer blames technological advancements for human insensitivity, "as their telescopes and microscopes, their tapes and radios become more sensitive, and individuals become blinder, harder of hearing and less responsive" (1978, p. 192). Designers generally think their way through their pens and pencils-they imagine what it would be like to "embody" the place before them-to whisper life into abstraction. Now we have a chance to think that through the boundary condition we can also think systemically.

Pallasmaa holds the ocularcentric bias and the consequent sensory imbalance responsible for the inhumanity of contemporary architecture and cities. He claims that the "art of the eye" has pushed us into isolation and detachment, creating imposing and thought-provoking structures that are not rooted in humanity. In this tradition the human body itself is abstracted to be used as a measure (proportions, units of measurement, etc.) or a metaphor (symbols, forms etc). As a result of this transgression, modernist design has "housed the intellect and the eye but left the body and the other senses, as well as our memories and dreams, homeless" (Pallasmaa, 1966, p. 6). Books such as Experiencing Architecture by Rasmussen (1962), Body, Memory, and Architecture by Bloomer (1977), and the Image of the City by Lynch (1960) have been some of the few significant efforts to address this lacuna. However, in the majority of mainstream literature, thought and design, the eye has continued to be "narcissistic, concerned only with self-expression, and detached from essential mental and societal connections, and nihilistic, deliberately advancing sensory and mental detachment and alienation" (Pallasmaa, 1966, p. 10). Thus, to design a place to have "Significant form," the designer must think of creating a lived domain with tactility that is attentive to sensibilities.

\section{Significant Form}

Architectural design is an expression of proposed place. At the beginning of the process a designer learns about the intentions of their clients and what they seek. They see the task, which might initially be a brief or a program, and must decide what this place should be like. Of course the designer does not come to the table without his or her own value system and an image bank of the significant places; the designer cannot mold the solution without reference to his or her past experiences. Places of significance are remembered and compared to what might be a future place in a complex dance of remembrance and possibilities (Downing, 2000). The resulting expressions are sketches, drawings, and virtual images of place; and, if the designer is successful-significant form. Thought is in the moment, expression is in time. The drawings present a symbol of how life can be lived.

Symbol making is uniquely human. Other animals may be able to conceptualize, but their ability to construct symbols and their associated meanings is limited. The evolution of symbols in higher-order consciousness (Edelman, 1992) serves the primary consciousness (that which is tied to the immediate and overwhelming present). Symbolization requires an ability to construct a socially based selfhood in order that the world is modeled in terms of "others." A state of direct awareness of the relationship among past, present, and future can be achieved only through higher order consciousness. Without symbol, this capacity is impossible and cannot develop. The development and evolution of symbolic memory enables us to be humans who elaborate, refine, connect, create, and remember (Downing, 2000).

In Philosophy in a New Key, Langer (1957) proposes two forms for human expression: discursive and presentational. Both forms employ a logical structure for relating symbols to whatever they are to mean. In language, the logical structure of discourse unfolds in a linear (or we say hermeneutic) manner, encompassing the ability to relate words and their meaning to concepts that they symbolically represent. The presentational form of expression is characterized by other art forms: music, painting, architecture, et cetera. A significant building or landscape is presented to us as an object or place; its sensate character-visual form and space, movement, sounds, texture, aromas-is its entire being. The logical structure is holistic, encompassing the ability to relate an experience to 
the symbolic import it presents to consciousness. What emerge from experiences of significant form are the symbols of sentience (contact, retreat, participation, identity, love, grace, fear, sensuousness, intellect, intimacy, growth, expansiveness, reflection, communing, and more), of life in all its conflicts and meanings. Significant form acts to present to the mind, the memory of things, occasions, and parables of life (Downing, 2000, p. 71). In other words, we present in presentational form of place, we experience significant form of living domain, vital import of environmental presence.

An example of significant form might be the American House through its historical evolution from its original, mostly European, birth. One of the first things that a European will notice upon visiting an American house will be the tendency to be more horizontal than vertical. The reasons for this tendency comes from theoreticians like Andrew Jackson Downing who wrote in the 1850 in American Cottages and Farmhouses about how an American house should sit in the landscape, compared to European traditions or the early American "temple" houses of the northeast. Essentially he begins with the theory of "utility, truth, and beauty," his conversion of "firmness, commodity, and delight" into a language that common folks could understand, but quickly moves to the landscape and the response to the quantity of landscape available to Americans at that early juncture. He suggests that the house should encompass and embrace the land and that the house should be formed as part of the land, sitting in it, not on it. Architects of the later 1800's who designed in the "stick and shingle style" (Scully, 1971) further developed the horizontality of space and opened the plan further so that one could view the land and sea throughout many conjoined rooms making most of the views available throughout the first floor plan. Of course this continued as Frank Lloyd Wright began his path and took the horizontal to its limit.

At "Redgate," this "horizontal" view is engaged through internal and external views that are developed. Originally the "living room" was cut off from the back yard (Fig. 4). By adding internal windows and an extension off the back bedroom a full horizontal view was possible. As a small house there was no need for a second floor-accentuating the sense of reaching out to the landscape, connecting it through "wings" and deep porches or verandas (Downing, 1850), that allowed for an edge condition to exist between house and landscape. Southern house plans were more formal, Downing called this house type a "villa" and pronounced it appropriate to its ecosystem; a hot and humid environment that called for floor to ceiling windows and doors (often with transepts), and often with two story verandas that would wrap around the house to keep the air as cool as possible as it moved across exposed skin. Shotgun houses were a modest version utilizing the same principles.

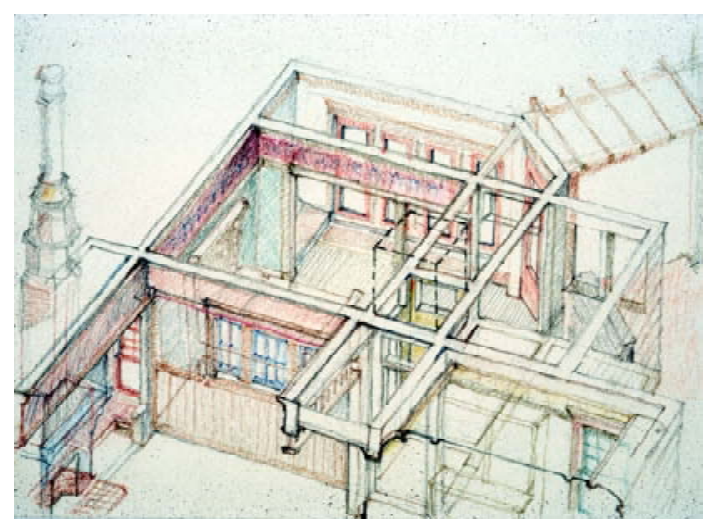

Figure 4: At "Redgate," an addition of internal voids of living space and an extension of edges lead the house to connect with the location by horizontal view.

If we focus on the edge, it becomes significant if it allows a symbol of spatial-relations to take place "in" a domain of juncture. Significant form of the edging interval manifests itself a medium of associative, spatial juxtapositions, manifestations of differences. In Steven Holl's Kiasma, we see a completely different embracing of the boundary condition. In this museum, series of places flow into each other, and boundaries are defined not by walls and doors, but by changing sensory environments-dark and light, sounds and quiet, movement and stillness. It is an example of using technology to create boundaries that are tangible, but not material. The building itself sits on its landscape as a picturesque sculpture-defining its boundary in concrete terms. Yet every once in a while, within the building, the boundary is pierced, and large windows are used to reconnect the museum viewer with the world outside. The body in the Kiasma experiences its environments through carefully crafted boundary conditions, sometimes by sounds, sometimes by views, and sometimes by immersing in darkness so that the body boundary fuses with the space enveloping it. This reflects the relationship between 
presentational forms of embodied, complex boundaries of interactions and the embodied aesthetics in places.

\section{Survival and the Edge of Place}

The aesthetics of embodied realism suggests that "survival" would necessarily be a critical issue if commodity and delight were thought of as necessary to the process of constructing places of significance rather than simply pleasant additions to a stripped-down version of "firmness." In the Origins of Architecture Pleasure by Hildebrand (1999) the thesis is clear, to survive as a species we must make places of beauty, places that peek our curiosity and need for exploration, and that give us pleasure and comfort, prospect and refuge. The theory of prospect and refuge, if thought of as a continuous experience, suggests that the "edge" or overlap "between" two "systems" is the most complex location that can be held. At the edge of place, we are "inbetween"-realms where choice, pause, and detached participation is possible. At Redgate the modest addition of a fireplace, an old-fashioned inglenook, added an edge that could be occupied-the true refuge (Fig. 5-6).

As edging intervals, inbetween domains are relevant to the conceptions of "manifestations of juxtapositions." According to Aldo van Eck (1968, p. 104), inbetween realms reconcile a spatial dichotomy and differences with transitional awareness, and therefore articulate "twin-phenomena" at once, "with respect to place and occasion." To be experienced as a place, the inbetweens must be identified as a containment of interrelating edges between places as the whole, a body of living form of intervals defined by organized complexity of edges.

Inbetween places, like other places, announce their own "significant forms" of pause, detached participation, and place fabrication through their presence of environmental tactility, associations, and juxtaposition demands. Inbetween places with tactile presence attract us to pause at the edges. A pause at a boundary is important because our meaningful experience of itineration through place is established into episodes: prior undergoing, present pause, and fore-preparation. A pause at an inbetween domain allows for detached participation with others, events, and environments nearby without invasions. With pause and detached participation, places in juxtaposition enable one to be interconnected into a network of environmental fabrication; the integrated whole emerges out of spatial sequences.

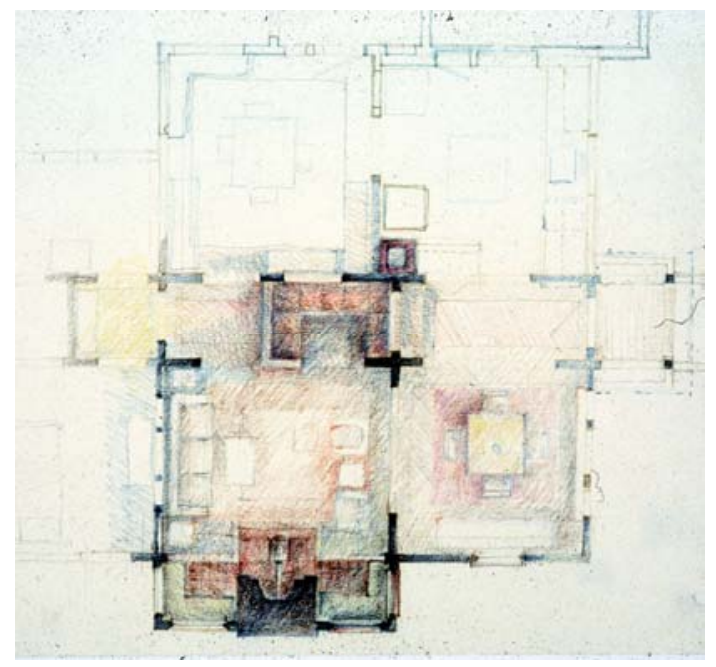

Figure 5\&6: In the Redgate House's living space, additions of a fireplace and an inglenook develop the edges of place for refuge.

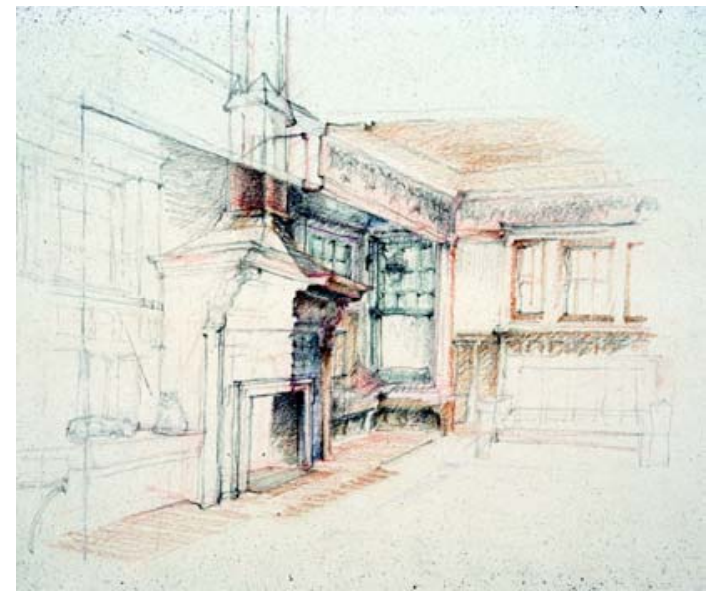

The inbetween mediums-sensual bodies, systemic building skins, and other living, edging entities-perform as vital layers of interconnection, making us assimilate new information and sustain our living in the complex system of neighborhoods. We as embodied entities become integrated with the environment by the embodied nature of spatial-relations (Lakoff \& Johnson, 2003, p. 30). We comprehend domains we live in through bodily metaphors to project, navigate, and create a place. To be a place, an 
environment has to manifest itself tangible reality responsive to all senses so that it can be identified as a distinct locality with presence. Environmental presence reinforces a symbolic image of a domain-"made visible, tangible, and sensible" (Langer, 1953 p. 95)-that is "Significant form" of place. We thus need vital places with lived sensibilities and imports to maintain our identity and to support life that they define for survival.

If we are to survive we need to make good, healthy, quality places-places that are necessary for a meaningful existence. Without the potential for dwelling in significant places, we would remain miserable in the entrails of the once and future Metropolis. Because we retain these necessities for a life worth living we can resist dying off as many other species have because they no longer shared meaningful information with their environments or the environments have become hostile to a species, i.e. a world paved over with sameness-something we might resist if we profess an architecture of the body, complete with all its senses, recognizing the complex system of body, mind, and place; a system of boundaries that weave in and out of the body and the environment, through the mind and the flesh. In short, if, as a profession, we invest in a thriving, interdependent system that embodies place within its ecological context, we will survive.

\section{Bibliography}

Bergson, H. 1922. Creative Evolution. Trans. Arthur Mitchell, London: MacMillan and Co Ltd.

Casey, E.S. 1998. The Fate of Place. Berkeley: University of California Press.

Collier, J. 2000. Emergence of the Internal Perspective in Western Science in Contemporary Philosophy. No. 8, pp. 245-253.

Downing, A. J. 1850. The Architecture of Country Houses. New York: D. Appleton \& Company.

Downing, F. 2000. Remembrance and the Design of Place. College Station: Texas A\&M Press.

Edelman, G. 1992. Bright Air, Brilliant Fire. New York: Perseus Books.

Hildebrand, G. 1999. Origins of Architectural Pleasure. Berkeley: University of California Press.

Horkheimer, M. 1978. Dawn and Decline: Notes 1926-1931

and 1950-1969. New York: Seabury Press.
Lakoff, G. \& Johnson, M. 1999. Metaphors We Live By. Chicago: University of Chicago Press.

Lakoff, G. \& Johnson, M. 2003. Philosophy of the Flesh: The Embodied Mind and Its Challenge to Western Thought. New York: Basic Books.

Langer, S. 1942-1979. Philosophy in a New Key. Cambridge: Harvard University Press.

Langer, S. 1953. Feeling and Form. New York: Charles Scribner's Sons.

Levin, D. 1993. Modernity and the hegemony of vision. Berkeley: University of California Press.

Maturana, H. \& Varela , F. 1987. The Tree of Knowledge: The Biological Roots of Human Understanding. Boston: Shambhala Publications Inc.

Maturana, H. \& Varela, F. 1980. Autopoiesis and Cognition: The Realization of the Living. Boston: Reidel.

Merleau-Ponty, M. 1964. The primacy of perception, and other essays on phenomenological psychology, the philosophy of art, history, and politics. Evanston: Northwestern University Press.

Merleau-Ponty, M. 1968. The Visible and the Invisible. Evanston: Northwestern University Press.

Mullarkey, J. 1999. The New Bergson. Manchester and London: Manchester University Press.

Pallasmaa, J. 1996. The eyes of the skin: architecture and the senses. London: Academics Editions.

Rasmussen, S. 2000. Experiencing Architecture. Cambridge: The MIT Press.

Scully, V. 1971. The Stick Style and the Shingle Style: Architectural Theory and Design from Downing to the Origins of Wright. New Haven: Yale University Press.

Van Eyck, A. 1968. Team 10 Primer. ed. Alison Smithson, Cambridge: MIT Press.

Varela F., Thompson, E., and Rosch E. 1991. The Embodied Mind: Cognitive Science and Human Experience. Cambridge: MIT Press.

Von Bertalanffy, L. 1981. A Systems View of Man: Collected Essays. ed. Paul A. LaViolette, Boulder: Westview Press. www.complexityandeducation.ualberta.ca/glossary.htm www.enolagaia.com/Tutorial1.html 